\title{
Pesquisas em diálogo: um olhar para os sentidos de políticas curriculares para a formação de professores
}

\begin{abstract}
Silva, Maria Angélica da ${ }^{1}$
Resumo

Almeida, Lucinalva Andrade Ataíde de 2

Compreendendo a pesquisa como um campo de produção discursiva que se configura no diálogo entre o já-dito e o que se está por dizer, este artigo buscou identificar os sentidos de Políticas Curriculares para a Formação de Professores que emergiram das publicações científicas referentes aos anos de 2003 a 2013 na ANPED e de 2002 a 2010 no EPENN, analisando-os frente ao aporte teórico-metodológico da Análise do Discurso (ORLANDI, 2010; 2012). Assim, estabelecemos diálogos entre as produções discursivas e os estudos de Oliveira e Pacheco (2013), Mainardes (2006), Lopes e Macedo (2011), entre outros, que nos auxiliaram a compreender o currículo e as políticas curriculares para a formação de professores enquanto discursos que tencionam intencionalidades. Diante disto, foi possível identificar um movimento de reconfiguração dos sentidos em torno do currículo e das políticas de formação de professores, uma vez que os sujeitos tecem a possibilidade da ressignificação e da recontextualização das políticas curriculares, pautadas na tensão e no conflito dos múltiplos interesses nos múltiplos contextos.
\end{abstract}

Políticas. Currículo. Produções Discursivas. Sentidos.

\section{Abstracto}

Entendiendo la pesquisa como un campo de producción discursiva que se define en el diálogo entre lo que se ha dicho y lo que se pretiende decir, este artículo busca identificar los sentidos de Políticas Curriculares para la Formación de los Maestros que surgieron en las publicaciones científicas situadas entre los años de 2003 hasta 2013 en la ANPED y las publicaciones del EPENN entre los años 2002 hasta 2010, los analizamos desde el marco teórico-metodológico del Análisis del Discurso (ORLANDI, 2010; 2012). Así que hemos establecido diálogos entre las producciones discursivas y los estudios de Oliveira y Pacheco (2013), Mainardes (2006), Lopes y Macedo (2011), entre otros, que nos han ayudado a compreender el currículo y las políticas curriculares destinadas a la formación del profesorado como discursos que confrontan distintas intencionalidades. De esa manera, fue posible identificar un movimento de reconstitución de los sentidos alrededor del currículo y de las politicas de formación de los maestros, ya que los sujetos tejen la posibilidad de resignificación y de recontextualización de las políticas curriculares, establecidas en la tensión y en el conflicto de los múltiples interesses en múltiples contextos.

\footnotetext{
${ }^{1}$ Doutoranda em Educação. Professora Substituta do Núcleo de Formação Docente da Universidade Federal de Pernambuco - Centro Acadêmico do Agreste, Integrante do Grupo de Pesquisa Discursos e Práticas Educacionais, Caruaru/PE, Brasil. E-mail: angelicasilva.ufpe@gmail.com.

${ }^{2}$ Doutora em Educação. Professora do Núcleo de Formação Docente e do Programa Pós-Graduação em Educação Contemporânea (CAA) e do Programa de Pós-Graduação em Educação (CE), Universidade Federal de Pernambuco, Coordenadora do Grupo de Pesquisa Discursos e Práticas Educacionais, Caruaru/PE, Brasil. E-mail: nina.ataide@gmail.com.
} 
Políticas. Currículo. Producciones Discursivas. Sentidos.

\section{O lugar da pesquisa em educação: Para que pesquisamos, para que escrevemos ${ }^{3}$ ?}

$\mathrm{O}$ ato de estudar e pesquisar nos coloca frente a um constante desafio, $\mathrm{O}$ de saber caminhar entre a realidade e tudo o que se produz sobre ela, para então, construir o novo conhecimento. Nesse sentido, "não falamos só com nossas palavras" (ORLANDI, 2007, p. 174), nossa fala se constitui pautada no interdiscurso, na relação com o já dito, que confere sentido aos novos sentidos que produzimos discursivamente.

Tomando por base estas ideias, escrevemos para sistematizar os olhares e compreensões acerca daquilo que nos rodeia, pesquisamos para contribuir e ampliar os sentidos já construídos sobre a realidade, uma vez que estudar é "estudar o estudo de quem, estudando, o escreveu" (FREIRE, 1981, p. 9).

Analogamente, lançar um olhar acerca do que vem sendo produzido no meio acadêmico possibilita o diálogo entre o já dito e o que se vai dizer, situando nossa pesquisa e discussão num contexto de produção de conhecimento. Além disso, ao estabelecer esse diálogo, as produções dos pesquisadores em educação ganham espaço social, não se restringindo à apresentação em eventos e sim cumprindo a função social da pesquisa, tal seja: a circulação e socialização dos novos conhecimentos, problematizando e retornando à sociedade.

Nesse sentido, este artigo tem como objetivo identificar os sentidos de Políticas Curriculares para a Formação de Professores que emergem das publicações científicas dos dois espaços discursivos, analisando-os frente ao aporte teórico-metodológico da Análise do Discurso (ORLANDI, 2010; 2013), frente ao diálogo com os estudos de Oliveira e Pacheco (2013), Mainardes (2006), Lopes e Macedo (2011) e Pacheco (2005), entre outros, que nos auxiliam a compreender o currículo e as políticas curriculares para a formação de

${ }^{3}$ Expressão embasada no livro de Garcia (2011). 
professores enquanto discursos que tencionam lutas e conflitos pela produção de sentidos e intencionalidades.

Sendo assim, para o desenvolvimento do presente estudo, após a leitura sistemática dos artigos da ANPED e do EPENN, realizamos uma categorização teórica dos núcleos de sentidos dos enunciados presentes nos discursos dos autores. Após essa fase que permitiu lapidar os enunciados, realizamos uma análise teórica dos sentidos revelados no movimento discursivo das produções.

Nessa direção, as publicações ao mesmo tempo em que são objeto de análise constituíram-se também como referencial teórico neste artigo, pois, compreendemos as produções como discursos em movimento, nos quais os sentidos se encontram imbricados entre si e com os contextos de produção.

Assim, nosso levantamento encontra-se delimitado aos Grupos de Trabalho (GT's) de Currículo e de Formação de Professores, por compreendermos que a partir dos trabalhos socializados nestes dois espaços podemos nos aproximar do que se tem produzido nos últimos anos em torno das Políticas de Currículo e de Formação. A opção pela ANPED e pelo EPENN se justifica pelo primeiro ser um evento nacional que responde pelas produções de Pós-Graduação e Pesquisa Educacional, e o segundo, com mesmo objeto e natureza, socializa discussões inscritas a nível regional (Norte e Nordeste). Nosso marco temporal encontra-se configurado de 2003 a 2013 na ANPED (17 trabalhos no GT de Formação e 17 trabalhos no GT de Currículo) e de 2002 a 2010 no EPENN (15 trabalhos no GT de Formação e 4 trabalhos no GT de Currículo).

Assim, este artigo encontra-se organizado em três seções, na primeira situamos o contexto de influência (BALL, 2001) em que estão inscritas as produções discursivas da ANPED e do EPENN, pois compreendemos que os discursos são produzidos dentro de um tempo-contexto e são influenciados por outros discursos produzidos em outros tempos-espaços. Ou seja, discutimos as tendências discursivas em torno das políticas de currículo e de formação de professores. 
Na segunda seção evidenciamos a circularidade de sentidos revelados nas produções discursivas da ANPED e na terceira seção tratamos do que nos dizem as produções do EPENN e do que temos a dizer sobre elas, concatenando, as análises em ambas as seções, discussões teóricas.

\section{Contexto de influência das produções discursivas da ANPED e do EPENN}

Os discursos que emergem dos trabalhos socializados na ANPED e no EPENN surgem em meio a um processo de internacionalização das políticas educacionais e curriculares, que se desencadeou em meio a um período de crise econômica deflagrada mundialmente, na qual o Ensino Superior passa a ser visto como um mecanismo para atender às demandas crescentes de uma sociedade globalizada. Este processo de internacionalização parte do pressuposto de que a formação precisa afastar-se do campo teórico e da produção do conhecimento, supervalorizando o campo "prático", com rebatimento em políticas efêmeras e pontuais, que priorizam a aplicabilidade imediata dos conhecimentos.

Temos compreendido que ao longo do tempo, as intencionalidades políticas, econômicas e sociais vão sendo traduzidas em discursos; discursos que explicitam alguns de seus objetivos de forma clara e outros surgem de forma subjacente, nas entrelinhas, e que para serem apreendidos e compreendidos requerem uma leitura de mundo que rompe com a ideia de que os discursos se produzem isoladamente, excluindo-se entre si a localidade e a globalidade no campo de produção de sentidos.

Nesse sentido, como nos aponta Mainardes (2006), as políticas são constituídas por um conjunto de processos que se articulam e movimentam-se constantemente, seja no contexto de influência (no qual as políticas são pensadas e discutidas), de produção (prescrição de textos no âmbito legal) e/ou contexto da prática (no qual ocorre a materialização da política). Em meio a estes contextos, encontram-se as políticas educacionais, influenciadas pela globalização, que ultrapassa o campo econômico e permeia nossa cultura e 
formação, atribuindo novos sentidos aos currículos e à formação profissional docente. Assim, ao pensar sobre a formação de professores percebemos que

o seu conteúdo e formato são objeto de contenda e de disputa entre os setores sociais [...] bem como entre os segmentos sociais que the dão o necessário apoio, tendo em vista o papel mediador exercido pelo Estado no atendimento às necessidades sociais, como a educação escolar (WEBER, 2003, p. 1146).

No âmbito da formação de professores assistimos à proliferação de instituições de Ensino Superior, em suas mais diversas modalidades (semipresencial, à distância) que anunciam uma formação rápida, de baixo custo e reconhecida, atraindo um público que vê a educação apenas como uma área de boa empregabilidade. Nesta linha, Almeida (2012) nos aponta, ao tratar do panorama das IES do Agreste pernambucano, que há

forte incidência de Instituições de Ensino Superior (IES) no
oferecimento da educação à distância (EAD), no agreste
pernambucano, pois, das 16 instituições existentes nesta
localidade, 10 fazem parte da modalidade EAD e apenas 6
provém cursos presenciais nas cidades onde estão situadas
suas filiais (p.32).

Conforme os resultados do relatório de pesquisa "Políticas curriculares para a formação de professores: Uma análise do currículo vivido pelas IES no curso de Pedagogia" (2012) este fato nos indica duas questões. A primeira delas se refere à democratização e interiorização do ensino superior, a segunda questão relaciona-se ao princípio que tem embasado esta democratização, tendo em vista que $60 \%$ das instituições são privadas na modalidade à distância, revelando aspectos crescentes de privatização e "mercadologização" do Ensino Superior. Sendo assim, percebemos que as políticas curriculares para a formação de professores também sofrem as influências da "onda de privatizações".

A grande ênfase hoje é aproximar e dar espaço ao investimento do setor privado, o que significa um afastamento maior de um processo de democratização e de acesso à educação, que é baseado no discurso que leva à redução do acesso, devido ao não financiamento institucional, dando lugar ao financiamento competitivo (ALMEIDA; LEITE; SANTIAGO, 2013, p. 127). 
Diante deste cenário, temos o movimento de resistência à política neoliberal e privatista da educação representado por entidades como o CNE, a ANPED entre outras, que representam um lócus de discussões e produções acerca do movimento de fortalecimento da democratização do acesso e da permanência aos espaços formativos, nas mais diversas modalidades, enviesados pela promoção da justiça e igualdade social. Ainda conforme as autoras, esse movimento de resistência procura superar a lógica mercadológica implantada nos discursos e nas reformas educacionais, que têm reforçado uma cultura formativa pautada pela "resolução de problemas sociais" e aplicabilidade dos conhecimentos produzidos.

Frente ao panorama discursivo em torno das políticas curriculares para a formação de professores que evidenciamos até aqui nos encaminhamos para a o trato dos sentidos revelados nas produções discursivas da ANPED e, posteriormente, do EPENN.

\section{A circularidade de sentidos nas produções discursivas da ANPED}

As produções discursivas que analisamos no período de 2003 a 2013 das reuniões da ANPED anunciaram a emergência de uma nova relação teoria e prática na formação, indicando a necessidade de novos paradigmas filosóficos, epistemológicos e pedagógicos, rumo à promoção da práxis na formação de professores (FERNANDES; FERNANDES, 2005).

Nessa direção, os estudos sobre as políticas curriculares para a formação de professores têm convergido para o atual contexto de internacionalização das políticas curriculares, que têm assumido um caráter neoliberal (OLIVEIRA, 2013), fundamentadas nas orientações dos organismos internacionais, reafirmando a segregação entre a teoria e a prática, mecanicizando a formação e engessando as práticas.

Em face disto, Silva, A. (2005) sinaliza a relação de forças e disputas entre os projetos liberal e democrático, que desde a segunda metade da década de 70 têm permeado os debates políticos e acadêmicos e influenciado na composição de paradigmas de sociedade e formação. Nesse sentido, vimos que "a produção 
das políticas públicas curriculares implica em um processo de articulação de demandas que são disputadas em torno de um projeto que se pretende hegemônico" (DIAS, 2011, p. 8).

Ao discutirmos sobre projeções e orientações recorremos ao currículo como um campo teórico-prático constituído por produções discursivas que se articulam e movimentam-se em torno do pensado e do vivido nos processos formativos. O currículo, portanto, mobiliza sentidos produzidos por diversos atores nos mais diversos contextos, imbuídos de marcas e influências dos discursos produzidos em outros momentos e tempos históricos.

Nesse sentido, é por compreender o currículo enquanto mecanismo que institui discursos que expressam as lutas pela produção de sentidos que evocamos a Análise do Discurso (AD), na perspectiva que nos apresenta Orlandi (2010), enquanto aporte teórico-metodológico para nossa discussão. Esta opção se justifica pôr a AD nos possibilitar uma relação contextualizada e histórica com o discurso, compreendendo que este não produz sentido absolutamente em si, mas, também, em relação com outros discursos e com os fatores influenciadores de sua produção, sejam eles a formação discursiva, a ideologia e o lócus do qual se enuncia do discurso. Desta maneira, torna-se possível compreender o currículo enquanto produção discursiva circunscrita em um tempo-espaço, mas que não se restringe e não se limita a ele, instaurado num movimento de circularidade discursiva em que o já-dito possibilita os novos-dizeres, dizeres estes que se constroem numa relação de polissemia (sentidos emergentes) e paráfrase (sentidos reconfigurados) que conferem um caráter cíclico, híbrido, incompleto e inconcluso no campo curricular.

Vimos então, o poder que as formações discursivas exercem na produção de novos dizeres-fazeres. De diferentes modos, conteúdos variados são incorporados aos textos políticos da formação docente, produzindo textos híbridos (LOPES; MACEDO, 2011). Nessa direção, pensar o currículo da formação de professores significa também estudar o contexto no qual os processos formativos encontram-se inseridos, buscando compreender os 
elementos históricos, sociais, econômicos que se imbricam e atribuem sentidos a estes processos, como versa Camargo (2006).

As pesquisas, como a de PAPI (2005), mostram uma nova cultura profissional imposta pelos discursos políticos nacionais e internacionais, e apontam

as incorporações de diferentes proposições, em forma de textos ou discursos, realizadas a partir de processos de articulação, desenvolvidos no âmbito do contexto de definição de textos, criam novos sentidos sobre a formação de professores e fortalecem outros, em busca da legitimidade da política para a formação docente no Brasil (DIAS, 2011, p. 7).

Nessa direção, as pesquisas têm mostrado a reestruturação das licenciaturas, através dos discursos dos documentos legais, impostos pelos moldes do poder público sob influência do neoliberalismo, que acabam por esvaziar e aligeirar a formação, que se encontra pautada pelos paradigmas modernos da aplicabilidade prática do saber.

Em contraponto temos percebido que as IES mobilizam forças para a ressignificação das políticas curriculares e elaboram seus currículos levando em conta o contexto e os sujeitos como produtores das mesmas (PASSOS, 2005); superando a distinção entre política e prática, como propõe Ferraço e Carvalho (2012). Trata-se de um movimento contra-hegemônico das universidades e entidades acadêmicas em prol de redefinições curriculares para a formação de professores pautadas nos estudos acerca desta profissão e suas especificidades (CAMARGO, 2006).

Conforme apontado por Melo (2004), essa caracterização das reformas das políticas curriculares para a formação de professores anunciam a construção de um novo paradigma, que pautados em outras pesquisas (FORSTER, 2004; ALMEIDA; BIAJONE, 2005), encontra-se alicerçado na epistemologia da prática. Tais estudos apoiam-se na premissa de que existe uma 'base de conhecimento' para o ensino, o que mobiliza muitos pesquisadores a investigar e sistematizar esses saberes na tentativa de compreender a genealogia da atividade docente e, assim, "convalidar um corpus de saberes mobilizados pelo professor com a 
intenção de melhorar a formação de professores" (ALMEIDA; BIAJONE, 2005, p. 1).

Estudos iniciados no final dos anos 80, nos Estados Unidos e Canadá, foram o prenúncio da abordagem dos saberes docentes pautados pela epistemologia da prática. Como vimos no decorrer dos nossos levantamentos, esta epistemologia da prática apresenta-se como elemento caracterizador da produção acadêmica na área da Formação de Professores, na última década, ganhando força também com os estudos curriculares que concebem o currículo como práxis. Nesse sentido, reafirma-se a importância dos estudos sobre os saberes docentes face à trajetória histórica de subalternização dos mesmos, processo no qual os professores são expropriados de sua capacidade criativa e criadora, vistos como meros consumidores dos saberes "academicamente validados" (ABDALLA, 2006).

Frente a este cenário, confere-se a formação inicial, para além do fornecimento de referenciais intelectuais e teóricos, o desafio da aproximação com o "que fazer" da profissão, por meio de componentes curriculares que realizem um diálogo que imbrica e movimenta teoria e prática.

Assim, a aprendizagem profissional docente pode seguir várias perspectivas partindo de diferenciados pressupostos que, segundo Oliveira e Pacheco (2013), podem estar centrados no conhecimento, na reflexividade, nos resultados ou no trabalho pedagógico. Estas diferentes abordagens do fazer profissional guiam a composição da organização curricular da formação de professores, inscrevendo-se num amplo campo de tensões e conflitos políticos e epistemológicos na construção de sentidos, como identificamos, a seguir, nas produções do EPENN.

\section{As produções discursivas do EPENN: $O$ que nos dizem e o que temos a dizer?}

Frente a esse movimento de transição paradigmática instaurado pela perspectiva da epistemologia da prática, anunciado nas produções analisadas anteriormente na ANPED, notamos a presença de discussões acerca dos entraves impostos pelas demandas curriculares para a formação de professores 
para a concretização das propostas formativas referenciadas pela epistemologia da prática.

Sendo assim, observamos a presença de estudos sobre as reformas curriculares (ROCHA, 2007) frente às novas demandas educacionais (MACEDO;

CABRAL NETO, 2011), versando sobre a influência da visão burocrática no processo de constituição das políticas curriculares para a formação de professores, fragilizando a formação com bases em um instrumental teórico que proporcione autonomia e reflexibilidade docente, componentes essenciais da formação pautada pela epistemologia da prática, defendida pela maioria dos pesquisadores nos encontros das publicações analisadas.

Nessa direção, observamos a configuração de novos discursos acerca da educação e da função social da escola, nos quais é atribuída à mesma a responsabilidade pela formação de uma sociedade mais qualificada e de indivíduos integralmente formados. Esses novos valores e atitudes, postos pelo projeto de sociedade globalizada, tendem a ser exigidos e incorporados na formação e na prática docente, nos remetendo aos diversos discursos acerca da formação que entram em embate nos campos teóricos, das políticas e dos contextos, de maneira interligada.

O estudo de Almeida et al. (2013), ao tratar das políticas curriculares para a formação de professores no contexto português e brasileiro, aponta as influências das organizações internacionais e dos discursos políticos na formulação destas políticas. De acordo com as autoras,

as exigências atribuídas à instituição escolar e aos profissionais que nela trabalham têm acompanhado os discursos sociais e políticos que reconhecem a sua importância na procura da concretização da igualdade de oportunidades de sucesso para todos os que a frequentam e a quem ela se destina (2013, p. 122).

Nessa direção, a formação de professores encontra-se relacionada com a organização do Estado e tensões políticas e econômicas de âmbito local e global. Assim, os contextos de influência, de produção e contexto da prática (MAINARDES, 2006) encontram-se relacionados e interdependentes. 
No contexto de influência, a noção de política como discurso evidencia as lutas de poder em que "compete-se" pela produção de sentidos e significados. Neste contexto, as experiências internacionais e exigências demandadas pelos fatores econômicos exercem influência na constituição dos discursos políticos, que por sua vez, apresentam um rebatimento no contexto de produção das políticas de formação de professores. Podemos observar no caso brasileiro, por exemplo, a "cultura da mimetização" das políticas, que consiste na transposição de experiências de outros países e implementação "forçada" no contexto brasileiro.

Esse fenômeno tem gerado constantes crises, essencialmente no contexto da prática, pois a partir do momento em que não é tomado como referência para produção das políticas, as tensões e os conflitos entre o dito, o escrito e o praticado afloram. Por sua vez, o contexto da prática atua não apenas como um mecanismo de execução das demandas políticas, mas também exerce um poder de resistência e ressignificação (MACEDO, 2001, 2005), problematizando as demandas em um movimento de ruptura daquilo que foi instituído, dando margem aos novos dizeres, ou seja, novos sentidos e significados configurados pelo chão das IES em torno das políticas de formação de professores.

Nesse movimento de resistência e ressignificação, evidencia-se a relação entre local e global. Mesmo os currículos das instituições sofrendo influências das demandas políticas e econômicas internas (mecanismos de avaliação e regulação do Estado) e externas ao país (Banco Mundial, FMI, UNESCO), ou seja, "da globalização, da organização do Estado e dos organismos internacionais" (ALMEIDA et al., 2013, p. 130), esses espaços formativos e os sujeitos não são meros consumidores de discursos. Apesar da ênfase das atuais políticas na expropriação dos saberes e a deslegitimação das práticas discursivas podemos enxergar o contexto da prática como tradutor, ressignificador e produtor de práticas discursivas. (SARTI, 2008).

Diante deste cenário, encontramos pesquisas sobre os discursos de resistência e ressignificação das IES (MACEDO, 2005) na formação de 
professores frente a este contexto das reformas educacionais do Estado (BATISTA NETO, 2005), que nas últimas décadas têm se delineado a serviço do neoliberalismo, pautadas nas premissas da globalização e mercantilização da educação. Sendo assim,

há um processo de reestruturação das políticas curriculares produzidas tanto no âmbito mundial quanto no local. Essa reestruturação provoca o advento de reformas, a partir de imperativos da legislação, procurando adequação da formação às novas exigências de flexibilidade da sociedade globalizada (ALMEIDA, 2007, p. 1).

Em um movimento discursivo de oposição a este cenário, as pesquisas têm apontado que as IES não atuam passivamente frente às novas demandas instituídas, os estudos "alicerçam-se na ideia de que as IES são espaços-tempos de ressignificações resistentes e propositivos aos modelos de formação de pedagogos(as)-professores(as)" (SILVA; SANTIAGO, 2007, p. 1), existindo, nesse sentido, uma interseção entre forças internas e externas, desembocadas nos discursos de resistências e ressignificações das IES face às políticas curriculares para a formação de professores.

Nessa direção, os estudos curriculares (4 trabalhos) versam sobre a relação entre o local e global nas políticas curriculares, sob a luz da abordagem do Ciclo das Políticas de Ball, trazendo uma compreensão de currículo como prática e movimento (EUGÊNIO, 2007). As mudanças curriculares têm sido percebidas, pelos autores, no sentido de articulação entre as dimensões teórica e prática, compreendidas como estruturantes nos projetos de curso, desembocando numa ampliação curricular voltada ao diálogo teoria-prática, como nos falam Camargo e Cabral (2011).

Com base nestas ideias, e numa perspectiva pós-crítica, o currículo e sua análise encontram-se envoltas pelas relações de poder, o que não significa limitar-se às relações econômicas do capitalismo, levando em conta o contexto, os aspectos históricos e culturais, entrecruzados de práticas discursivas de significação. 
O sentido e o significado, entretanto, não são produzidos de forma isolada, circulando como átomos, como unidades independentes. O significado e o sentido tampouco existem como ideia pura, como pensamento puro, fora do ato de sua enunciação, de seu desdobramento em enunciados, independentemente da matéria significante, de sua marca material como linguagem (SILVA, 2010, p. 18).

Nessa direção, Orlandi (2007) argumenta que não existe transparência no discurso tampouco uma única maneira de interpretá-lo. O dito, o não-dito e o silêncio entrelaçam-se e formam um movimento que merece ser compreendido articuladamente ao contexto. Sendo assim, o currículo, como texto-discursoprática, expressa um campo de conflitos e tensões e avoca o desvelamento dos sentidos em todas suas formas de expressão. Portanto, compreender esses sentidos e seus movimentos de produção constitui-se como uma das funções das teorias curriculares.

Nesse sentido, enxergamos na abordagem do Ciclo das Políticas de Ball (MAINARDES, 2006) os elementos teóricos que podem nos servir de lentes para compreender e analisar o currículo como fenômeno educativo complexo. Esta abordagem parte da premissa de que o currículo é um processo de recontextualização constante, permeado por diversos sentidos e significados atribuídos pelos diversos atores que o compõem.

Sendo assim, as políticas educacionais, políticas curriculares, o currículo e as práticas curriculares solicitam do pesquisador teorias e métodos de análise que valorizem o lugar do texto e do discurso na compreensão do fenômeno educativo, possibilitando o emergir dos sentidos que se fazem presentes nos textos, nas práticas, nos ditos, nos não-ditos e também naquilo que é silenciado no movimento curricular. Nessa direção, “o currículo é, ele mesmo, uma prática discursiva. Isso significa que ele é uma prática de poder, mas também uma prática de significação, de atribuição de sentidos" (LOPES; MACEDO, 2011, p. 41), ou seja, currículo é manifestação de sentidos que tencionam intencionalidades diversas.

Nessa direção, currículo é compreendido como uma prática produtiva no sentido de possibilitar o diálogo, a construção e a socialização de 
conhecimentos, pelo fato de ser também um espaço de problematização do saber, da cultura e da sociedade. Portanto, estudar o currículo significa compreender que ele é mais que um conceito, o currículo possui várias dimensões, podendo ser visto a partir de sua função social, ser analisado como campo prático, como atividade discursiva, que estão interligadas entre si, conforme reportado por Sacristán (2000).

Sendo assim, vemos o currículo não como um conceito, mas como um conjunto de práticas entrecruzadas, desenvolvidas por sujeitos que ao mesmo tempo em que produzem e discursam sobre o currículo são também formados por ele.

\section{Considerações Finais}

Figura-nos como elemento preponderante o papel e o lugar do diálogo com as pesquisas para situar nosso debate no contexto de produção acadêmica, uma vez que restou claro as marcas discursivas dos já-ditos no âmbito das discussões sobre as políticas curriculares para a formação de professores, nos possibilitando a produção de outros dizeres e construção de outros sentidos.

Nessa direção, as análises das produções discursivas da ANPED e do EPENN, estabelecidas neste artigo, nos revelaram um movimento de resistência e ressignificação das IES e dos cursos de formação de professores frente aos processos de internacionalização das políticas curriculares, que tem apresentado um caráter mercadológico e neoliberal para atender as demandas da sociedade exponencialmente globalizada.

Neste contexto, as discussões sobre currículo e políticas de formação de professores tem ganhado destaque enquanto espaços de produção de sentidos aos quais são conferidos os desafios de reestabelecer o elo entre teoria e prática no aprendizado profissional e produzir sentidos que rompam com a incidência da lógica capitalista nos processos de formação docente.

Nesse cenário de efemeridade dos sentidos acerca do currículo e do campo de luta e interesses que essa área do conhecimento representa, tem se tornado imprescindível reconhecer o seu lugar na construção e direcionamento de projetos de sociedade e educação. Tomando por base estas ideias, discutir 
currículo significa discutir a produção de sentidos permeada por questões ideológicas, políticas e epistemológicas.

Sendo assim, as discussões curriculares concatenadas às discussões da formação inicial de professores representam um exercício de práxis voltado para a superação do caráter estático dos discursos que tentam engessar os sentidos que transitam entre o já-dito e o que se está por dizer no âmbito curricular. Contudo, as possibilidades dos novos dizeres emergem da vivência do currículo enquanto unidade entre teoria-prática, que nos revela um sentido cíclico e híbrido do lugar, importância e contribuição do currículo, em suas mais diversas dimensões, na formação de professores.

\section{Referências}

ALMEIDA, Lucinalva Andrade Ataíde de. Políticas Curriculares para a formação de professores: uma análise do currículo vivido pelas IES no curso de Pedagogia. Relatório Técnico Final. Caruaru: CNPq, 2012.

ALMEIDA, Lucinalva; LEITE, Carlinda; SANTIAGO, Eliete. Um olhar sobre as políticas curriculares para formação de professores no Brasil e em Portugal na transição do século XX para o XXI. Revista Lusófona de Educação, Porto - Portugal, v. 23, n. 23, março/junho. 2013. pp. 119-135.

BALL, Sthefen. Diretrizes Políticas Globais e Relações Políticas Locais em Educação. Currículo sem Fronteiras. Porto Alegre, v. 1, n. 2, pp. 99-116, Jul/Dez, 2001.

BATISTA NETO, José. Formação de professores no contexto das reformas educacionais e do estado. Trabalho apresentado ao $17^{\circ}$ Encontro de Pesquisa Educacional do Nordeste, Belém - Pará, Anais... 2005.

CAMARGO, Arlete Maria Monte de; CABRAL, Maria da Conceição Rosa. Mudanças curriculares nos cursos de formação de professores. Trabalho apresentado ao $20^{\circ}$ Encontro de Pesquisa Educacional do Norte e Nordeste, Manaus - Amazonas, Anais... 2011.

DIAS, Rosanne Evangelista. Política curricular de formação de professores: Um campo de disputas. Trabalho apresentado a 34ํㅡㄹ Reunião da Associação Nacional de Pós-Graduação e Pesquisa em Educação, Natal - RN, Anais... 2011.

EUGÊNIO, Benedito Gonçalves. Políticas curriculares: Algumas considerações. Trabalho apresentado ao 18을 Encontro de Pesquisa Educacional do Norte e Nordeste, Maceió - Alagoas, Anais... 2007.

FERNANDES, Cleoni Maria Barboza; FERNANDES, Sônia Regina de Souza. As questões da prática pedagógica como componente curricular nas licenciaturas. Trabalho apresentado a 28ª Reunião Anual da Associação Nacional de PósGraduação e Pesquisa em Educação, Caxambu- Minas Gerais, Anais... 2005.

FERNANDES, Cleoni Maria Barboza; FERNANDES, Sônia Regina de Souza. A didática em re-construção como mediação entre a formação pedagógica e a formação 
específica: Uma possibilidade em aberto na reconfiguração das licenciaturas? Trabalho apresentado a 31 Reunião da Associação Nacional de Pós-Graduação e Pesquisa em Educação, Caxambu - Minas Gerais, Anais... 2008.

FORSTER, Mari Margarete dos Santos. Os lugares e os sentidos da Formação Docente. Trabalho apresentado a 27ํㅡㄹ Reunião da Associação Nacional de PósGraduação e Pesquisa em Educação, Poços de Caldas - Minas Gerais, Anais... 2004.

FREIRE, Paulo. Ação cultural para a liberdade e outros escritos . Rio de Janeiro: Paz e Terra. $5^{\text {a }}$ edição. 1981

GARCIA, Regina Leite (Org.). Para quem pesquisamos. Para quem escrevemos O impasse dos intelectuais. 3. ed. São Paulo: Cortez, 2011.

LEITE, Carlinda. Currículo, didática e formação de professores: algumas ideias conclusivas. In: OLIVEIRA, Maria Rita; PACHECO, José Augusto (Orgs.). Currículo, Didática e Formação de Professores. Campinas, SP: Papirus, 2013.

LOPES, Alice Casimiro; MACEDO, Elizabeth. Teorias de Currículo. São Paulo: Cortez, 2011.

MACEDO, Lucinalva da Silva. As políticas de formação de professores para o ensino fundamental: Legitimação e Resistência. 2001. Dissertação (Mestrado em Educação) - Universidade Federal de Pernambuco, Recife, 2001.

MACEDO, Lucinalva da Silva. O discurso da resistência e a formação de professores. Trabalho apresentado ao $17^{\circ}$ Encontro de Pesquisa Educacional do Norte e Nordeste, Belém- Pará, Anais... 2005.

MACÊDO, Valcinete Pepino de; CABRAL NETO, Antônio. Formação de professores e novas demandas educacionais. Trabalho apresentado ao 20 튼 Entro de Pesquisa Educacional do Nordeste, Manaus - Amazonas, Anais.... 2011.

MAINARDES, Jefferson. Abordagem do Ciclo de Políticas: Uma contribuição para a análise de Políticas Educacionais. Educação e Sociedade, Campinas, vol. 27, n. 94, jan./abr. 2006. pp. 47-69.

MELO, Ferreira Geovana. Formar Professores: Para que? Para quem? Trabalho apresentado a $27^{\circ}$ Reunião da Associação Nacional de Pós-Graduação e Pesquisa em Educação, Poços de Caldas - Minas Gerais, Anais... 2004.

MEDEIROS, Maria das Neves de; OLIVEIRA, Rosalba Lopes de. A didática sob a ótica dos alunos do curso de pedagogia do ifesp: Questões iniciais. Trabalho apresentado ao $20^{\circ}$ Encontro de Pesquisa Educacional do Norte e Nordeste, Manaus - Amazonas, Anais... 2011.

ORLANDI, Eni Puccineli. Autoria, leitura e efeitos do trabalho simbólico.

Campinas, SP: Pontes,2012.

ORLANDI, Eni Puccineli. Análise de Discurso: Princípios e procedimentos. Campinas, SP: Pontes Editores, 2010.

OLIVEIRA, Maria Rita; PACHECO, José Augusto (Orgs.). Currículo, Didática e Formação de Professores. Campinas, SP: Papirus, 2013.

OLIVEIRA, Veronica Borges de. Currículo e formação de professores: Discursos da profissionalização docente. Trabalho apresentado a 36 $6^{\mathrm{a}}$ Reunião Anual da Associação Nacional de Pós-Graduação e Pesquisa em Educação, Goiânia - Goiás, Anais... 2013. 
PACHECO, José Augusto. Estudos Curriculares para a Compreensão Crítica da Educação. Porto, Portugal: Porto Editora, 2005.

PACHECO, José Augusto. Políticas de Formação de Educadores e Professores em Portugal. In: OLIVEIRA, Maria Rita; PACHECO, José Augusto (Orgs.). Currículo, Didática e Formação de Professores. Campinas, SP: Papirus, 2013. pp. 45-68.

PAPI, Silmara de Oliveira Gomes. Desenvolvimento Profissional de Professores:

Cultura Profissional e Desafios da Profissionalização. Trabalho apresentado a 28응

Reunião da Associação Nacional de Pós-Graduação e Pesquisa em Educação,

Caxambu - Minas Gerais, Anais... 2005.

PASSOS, Carmensita Matos Braga. Elaboração dos novos currículos das licenciaturas: Negociações disputas e relações de poder. Trabalho apresentado a $28^{\circ}$ Reunião da Associação Nacional de Pós-Graduação e Pesquisa em Educação, Caxambu - Minas Gerais, Anais... 2005.

SACRISTÁN, José Gimeno. O Currículo - Uma reflexão sobre a prática. Porto Alegre: Artmed, 2000.

SILVA, Andréia Ferreira da. A formação de professores para a educação básica no Brasil: Projetos em disputa (1987-2001). Trabalho apresentado a 28을 Reunião da Associação Nacional de Pós-Graduação e Pesquisa em Educação, Caxambu - Minas Gerais, Anais... 2005.

ROCHA, Áurea Maria Costa. Formação dos professores no curso de pedagogia um olhar a partir da reforma curricular. Trabalho apresentado ao $18^{\circ}$ Encontro de Pesquisa Educacional do Nordeste, Maceió - Alagoas, Anais... 2007.

WEBER, Silke. Profissionalização Docente e Políticas Públicas no Brasil. Educação e Sociedade, Campinas, vol. 24, n. 85, Dezembro, 2003. pp. 1125-1154. 